Case Report

\title{
First Case of Tricuspid Valve Endocarditis Caused by Gemella bergeri
}

\author{
Orathai Pachirat, ${ }^{1}$ George Watt, ${ }^{2}$ and Burabha Pussadhamma ${ }^{1}$ \\ ${ }^{1}$ Division of Cardiovascular Medicine, Faculty of Medicine, Khon Kaen University, Khon Kaen 40002, Thailand \\ ${ }^{2}$ International Emerging Infection Program (IEIP), Thailand MOPH-US CDC Collaboration, Nonthaburi 10110, Thailand \\ Correspondence should be addressed to Orathai Pachirat; orathai@hotmail.com
}

Received 12 June 2015; Accepted 16 July 2015

Academic Editor: Florian Thalhammer

Copyright (c) 2015 Orathai Pachirat et al. This is an open access article distributed under the Creative Commons Attribution License, which permits unrestricted use, distribution, and reproduction in any medium, provided the original work is properly cited.

Gemella bergeri is a Gram-positive cocci species arranged in pairs and composes the normal flora of oral cavity, digestive and urinary tract. Several species of Gemella are known to cause endocarditis. Here, we report the first case in Thailand of G. bergeri endocarditis whose blood culture was negative using routine methods but was positive by PCR identification of bacteria in the affected valve. A 37-year-old male presented with prolonged fever, weight loss, and dyspnea on exertion. By transthoracic echocardiography, he was suspected of having infective endocarditis of the tricuspid valve. The patient underwent tricuspid valve repair and vegetectomy. Routine hospital blood cultures were negative but G. bergeri was identified by PCR/sequencing of the heart valve tissue.

\section{Introduction}

Gemella bergeri, one of the six species belonging to the genus Gemella, is a family of Gram-positive cocci arranged in pairs and composes the normal flora of the oral cavity and digestive and urinary tract. It was isolated for the first time by Collins et al. in 1998 from the blood cultures of six febrile patients, three of whom had endocarditis [1]. Since then, only seven cases of $G$. bergeri endocarditis have been reported so far [1-4]. Predisposing cardiac abnormalities such as mitral valve prolapse, Tetralogy of Fallot, bicuspid aortic valve (BAV), and rheumatic heart disease seem to be the most important risk factors [2-5]. We describe herein a case of $G$. bergeri endocarditis of tricuspid valve with underlying tricuspid valve cleft. The causative pathogen was detected and identified by PCR/sequencing of the DNA of the cardiac valve tissue of the patient $[6,7]$.

\section{Case Presentation}

2.1. Patient Information. A 37-year-old male poultry farmer was admitted to a provincial hospital with prolonged fever for a month, weight loss, and shortness of breath and suspected of having infective endocarditis (IE). He was transferred to our cardiac center for evaluation. He denied any history of intravenous drug use, smoking, drinking alcohol, or cardiac abnormality.

2.2. Clinical Findings. On examination, his temperature was $38^{\circ} \mathrm{C}$, blood pressure was $120 / 80 \mathrm{mmHg}$, respiratory rate was 20/min, and heart rate was 92 beats/min with a regular rhythm, no cyanosis with distension of the jugular vein, and prominent $\mathrm{V}$ wave. Cardiac examination revealed pansystolic murmur of grade 3/6 at left lower sternal area, mild hepatomegaly consistent with tricuspid regurgitation, and no signs of cardiac failure. Other systemic examinations showed no evidence of peripheral stigmata of IE.

2.3. Diagnostic Focus. Laboratory data included normal white blood cell count and blood chemistry. A transthoracic echocardiogram (TTE) revealed large mobile vegetation on the tricuspid valve (Figure 1) with moderately severe tricuspid regurgitation by Doppler-color flow and normal left ventricular function. Those findings were consistent with IE of the tricuspid valve. Three sets of routine aerobic blood cultures were negative. 

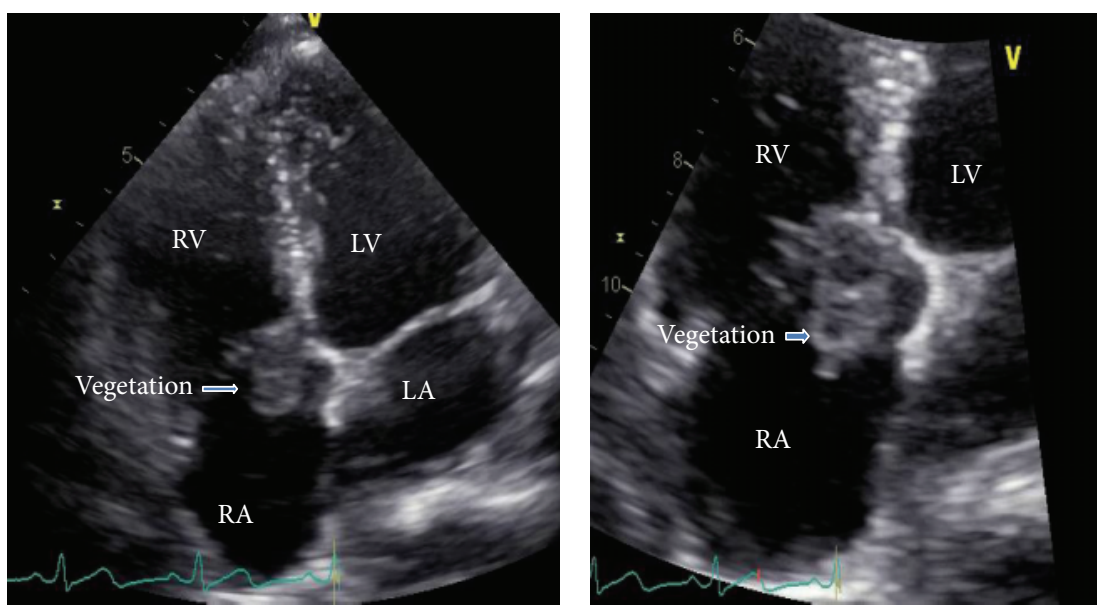

FIGURE 1: Transthoracic echocardiogram: four chambers' view of the heart showing large vegetation attached at tricuspid valve along right atrial surface. RA: right atrium; LA: left atrium; RV: right ventricle; LV: left ventricle.

2.4. Therapeutic Intervention and Follow-Up. The patient received intravenous antibiotics on the first day of hospitalization and was referred to cardiothoracic surgeons for surgical intervention due to unresolved fever after 8 days of medical treatment with large highly mobile vegetation; the patient underwent tricuspid valve repair with vegetectomy and it was found that the patient had tricuspid valve cleft as underlying heart disease. G. bergeri was demonstrated in heart valve tissue by real-time PCR. One month after surgery, the patient was discharged from the hospital with good outcome.

\section{Discussion}

Gemella bergeri is facultatively anaerobic, slow growing fastidious bacteria [8]. The importance of this organism and other Gemella species as a causative agent for human infectious diseases has been increasingly recognized.

One of the most recognized infections due to Gemella species is IE [9]. There are several cases reported in the literature that have highlighted the importance of preexisting heart valves disease or poor dental hygiene in patients [10-12]. It is highly sensitive to penicillin $\mathrm{G}$ or ampicillin and has lowlevel resistance to aminoglycosides. The outcome is generally good with appropriate antibiotic therapy [13].

To the best of our knowledge, there are only seven previously reported cases of IE due to G. bergeri. Collins et al. [1] reported a series of three cases of IE due to G. bergeri in 1998, which led to the identification of this bacterium as new species. Elsayed and Zhang [2] described another case of $G$. bergeri IE in an adult patient with bicuspid aortic valve that was complicated by valve ring abscess. Logan et al. [3] reported the first case of pediatric IE caused by G. bergeri in a boy with Tetralogy of Fallot and pulmonary atresia. Virgilio and Chieco [5] reported the sixth case of G. bergeri IE in an adult man with bicuspid aortic valve, using molecular diagnosis with 16S rRNA gene sequence analysis. Hussain et al. [4] reported neurological complications of $G$. bergeri IE in a young patient with rheumatic heart disease that was complicated by embolic stroke and rupture of mycotic aneurysm with bad outcome. All but the last reported case [4] showed good response to medical treatment and had good clinical outcome.

We describe herein the first case of G. bergeri IE in Thailand. All other previously reported cases of G. bergeri endocarditis in the literature had underlying cardiac conditions [2-5] and were the IE of the left side of the heart. Our patient has tricuspid valve cleft with the first case of right sided endocarditis which highlights the importance of molecular methods for the identification of microorganism directly from the heart valve tissue especially in blood culture-negative IE cases.

\section{Conflict of Interests}

The authors declare no conflict of interests.

\section{Acknowledgments}

The authors thank the following investigators for their invaluable help with this study: from the University of the Mediterranean, Marseille, France: Pierre-Edouard Fournier and Didier Raoult; from IEIP, Nonthaburi, Thailand: Somsak Thamthitiwat and Susan A Maloney; from Khon Kaen University: Viraphong Lulitanond, Sompop Prathani, and Anucha Puapairoj. The authors would like to thank Professor Dr. Yukifumi Nawa, Research Affairs, Faculty of Medicine, Khon Kaen University, for editorial assistance.

\section{References}

[1] M. D. Collins, R. A. Hutson, E. Falsen, B. Sjöden, and R. R. Facklam, "Gemella bergeriae sp.nov, isolated from human clinical specimens," Journal of Clinical Microbiology, vol. 36, no. 5, pp. 1290-1293, 1998.

[2] S. Elsayed and K. Zhang, "Gemella bergeriae endocarditis diagnosed by sequencing of rRNA genes in heart valve tissue," 
Journal of Clinical Microbiology, vol. 42, no. 10, pp. 4897-4900, 2004.

[3] L. K. Logan, X. Zheng, and S. T. Shulman, "Gemella bergeriae endocarditis in a boy," Pediatric Infectious Disease Journal, vol. 27, no. 2, pp. 184-186, 2008.

[4] K. Hussain, J. Abubaker, Z. Omar Al Deesi, and R. Ahmed, "Unreported neurological complications of Gemella bergeriae infective endocarditis," BMJ Case Reports, 2014.

[5] E. Virgilio and P. A. Chieco, "Sixth case of infective endocarditis caused by Gemella bergeri," Brazilian Journal of Infectious Diseases, vol. 18, no. 4, article 467, 2014.

[6] P. Brouqui and D. Raoult, "New insight into the diagnosis of fastidious bacterial endocarditis," FEMS Immunology and Medical Microbiology, vol. 47, no. 1, pp. 1-13, 2006.

[7] P.-E. Fournier, F. Thuny, H. Richet et al., "Comprehensive diagnostic strategy for blood culture-negative endocarditis: a prospective study of 819 new cases," Clinical Infectious Diseases, vol. 51, no. 2, pp. 131-140, 2010.

[8] K. Ruolf, "Aerococcus, Abiotrophia, and other infrequently isolated aerobic catalase-negative, gram-positive cocci," in Manual of Clinical Microbiology, P. R. Murray, E. J. Baron, J. H. Jorgensen, M. A. Pfaller, and R. H. Yolken, Eds., pp. 434-444, American Society for Microbiology, Washington, DC, USA, 8th edition, 2003.

[9] P. Brouqui and D. Raoult, "Endocarditis due to rare and fastidious bacteria," Clinical Microbiology Reviews, vol. 14, no. 1, pp. 177-207, 2001.

[10] M. O. Al Chekakie, A. Heroux, M. Montpetit, and H. Nemeh, "Gemella morbillorum prosthetic valve endocarditis," Congestive Heart Failure, vol. 15, no. 6, pp. 291-292, 2009.

[11] N. Avgoustidis, C. V. Bourantas, G. P. Anastasiadis, N. Sipsas, and D. Pikazis, "Endocarditis due to Gemella haemolysans in a patient with systemic lupus erythematosus," Journal of Heart Valve Disease, vol. 20, no. 1, pp. 107-109, 2011.

[12] R. Khan, C. Urban, D. Rubin, and S. Segal-Maurer, "Subacute endocarditis caused by Gemella haemolysans and a review of the literature," Scandinavian Journal of Infectious Diseases, vol. 36, no. 11-12, pp. 885-888, 2004.

[13] A. Buu-Hoi, A. Sapoetra, C. Branger, and J. F. Acar, "Antimicrobial susceptibility of Gemella haemolysans isolated from patients with subacute endocarditis," European Journal of Clinical Microbiology, vol. 1, no. 2, pp. 102-106, 1982. 


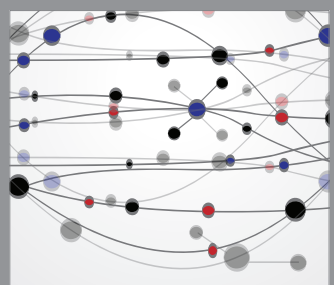

The Scientific World Journal
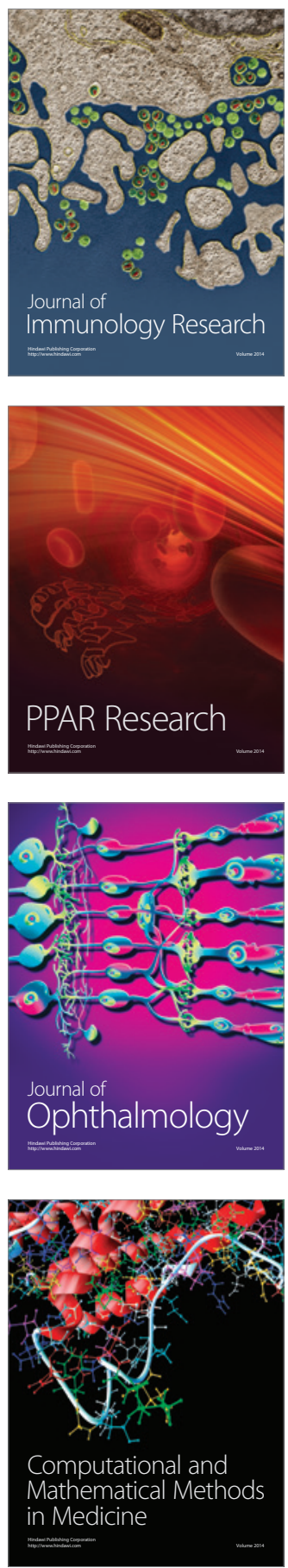

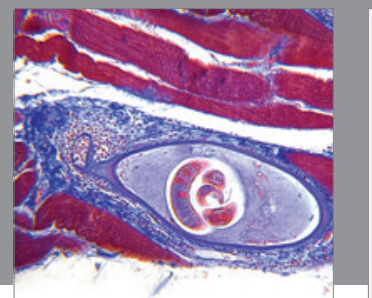

Gastroenterology

Research and Practice
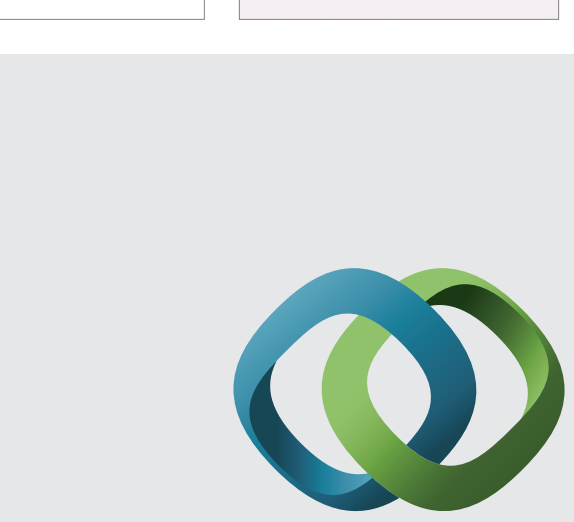

\section{Hindawi}

Submit your manuscripts at

http://www.hindawi.com
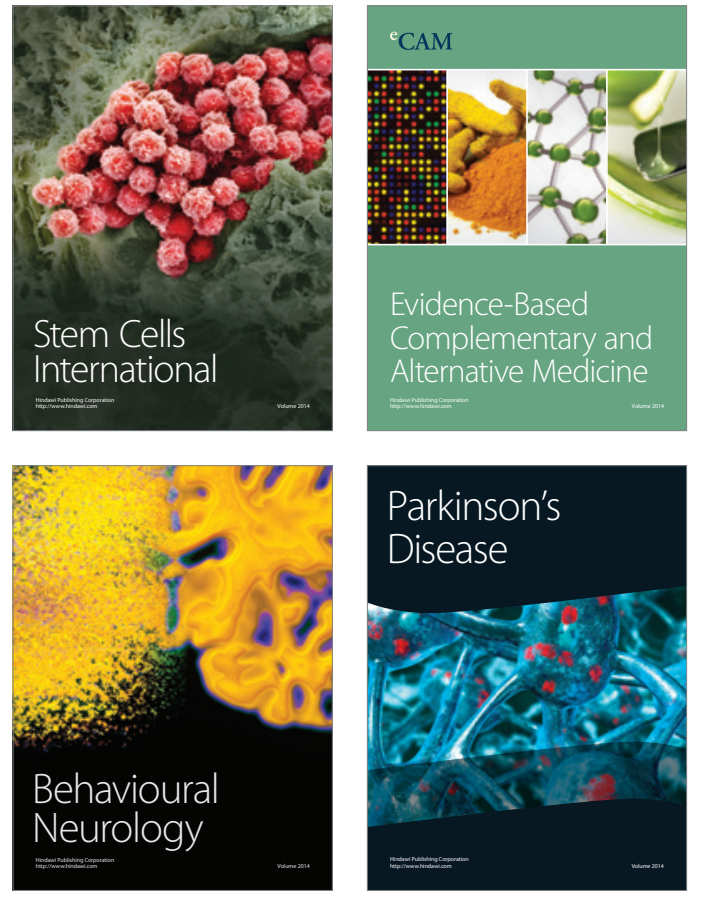
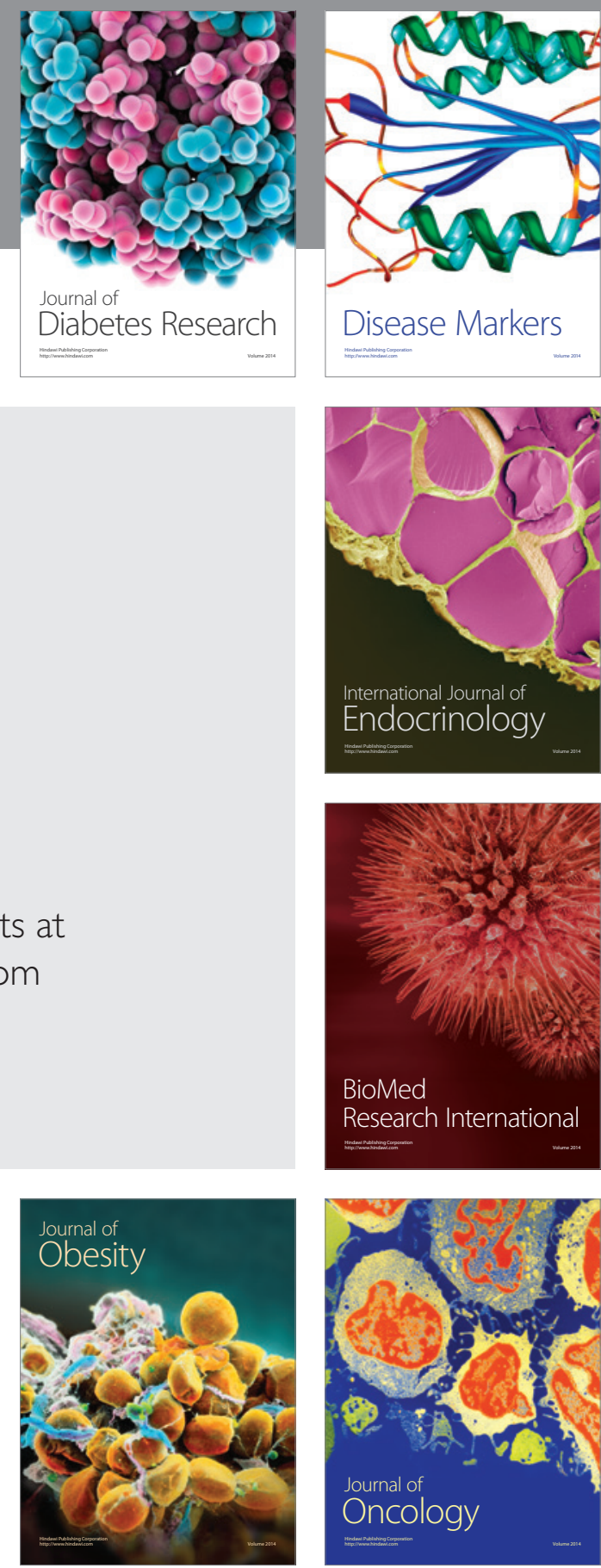

Disease Markers
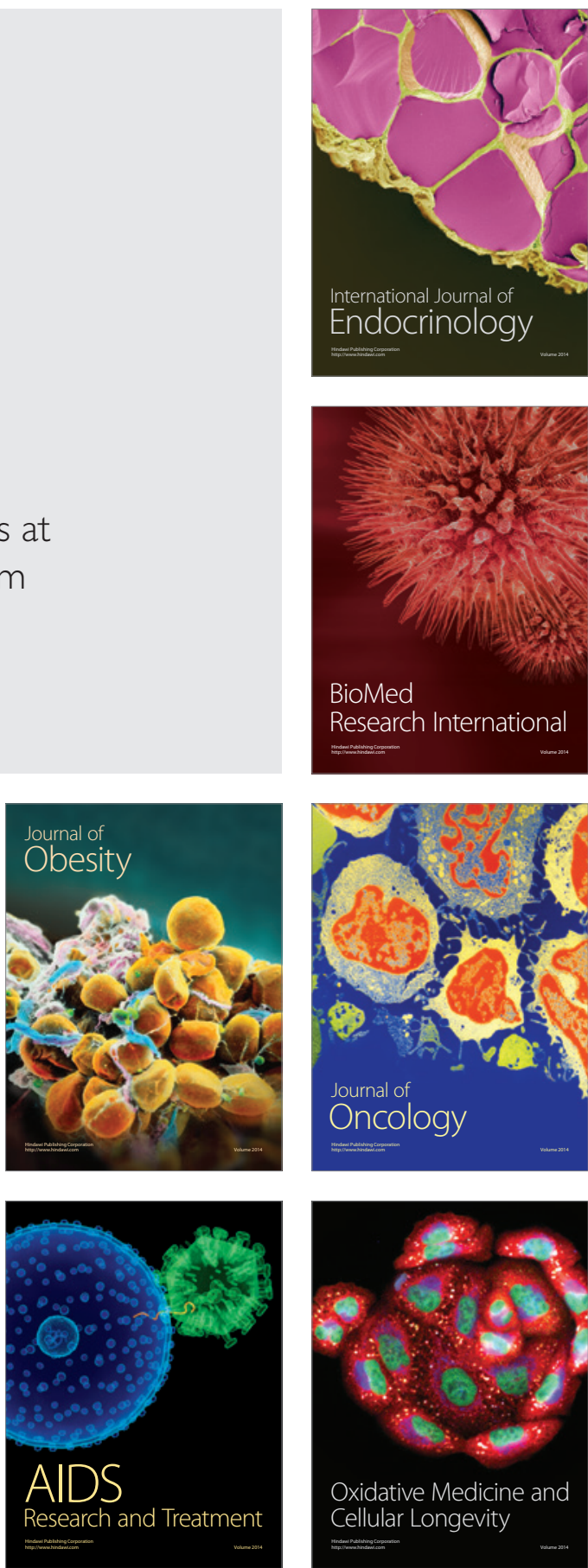